Marquette University

e-Publications@Marquette

College of Education Faculty Research and

Publications

Education, College of

$1-1-2015$

\title{
Incidence of Behavior Problems in Toddlers and Preschool Children from Families Living in Poverty
}

Casey A. Holtz

Marquette University

Robert A. Fox

Marquette University, robert.fox@marquette.edu

John R. Meurer

Medical College of Wisconsin

Accepted version. The Journal of Psychology, Vol. 149, No. 2 (2015): 161-174. DOI. (C) 2015 Taylor \& Francis (Routledge). Used with permission. 


\title{
Incidence of Behavior Problems in Toddlers and Preschool Children from Families Living in Poverty
}

\author{
Casey A. Holtz \\ Wisconsin Lutheran College \\ Milwaukee, WI \\ Robert A. Fox \\ College of Education, Marquette University \\ Milwaukee, WI \\ John R. Meurer \\ Medical College of Wisconsin \\ Milwaukee, WI
}

\begin{abstract}
:
Few studies have examined the incidence of behavior problems in toddlers and preschool children from families living in poverty. The available research suggests behavior problems occur at higher rates in children living in poverty and may have long-term negative outcomes if not identified and properly treated. This study included an ethnically representative sample of 357 children, five years of age and younger, from a diverse, low-income, urban area. All families' incomes met the federal threshold for living in poverty. Behavior problems were assessed by parent report through a questionnaire specifically designed for low-income families. Boys and younger children were reported as demonstrating a higher rate of externalizing behaviors than girls and older children. The overall rate of children scoring at least one


NOT THE PUBLISHED VERSION; this is the author's final, peer-reviewed manuscript. The published version may be accessed by following the link in the citation at the bottom of the page.

standard deviation above the sample's mean for challenging behaviors was $17.4 \%$ and was not related to the child's gender, age or ethnicity. This study also sampled children's positive behaviors, which is unique in studies of behavior problems. Gender and age were not related to the frequency of reported positive behaviors. Ethnicity did influence scores on the positive scale. African American children appeared to present their parents more difficulty on items reflecting cooperative behaviors than Caucasian or Latino children. The implications of the study are discussed based on the recognized need for universal screening of behavior problems in young children and the small number professional training programs targeting the identification and treatment of early childhood behavior problems, despite the availability of evidence-based treatment programs tailored to young children in low-income families.

Keywords: behavior problems, poverty, toddlers and preschooler children.

Behavior problems in toddlers and preschoolers have been a recent focus in the literature due to the growing recognition of disruptive behaviors occurring in this younger population (Biglan, Mrazek, Carnine, \& Flay, 2003), the non-transient nature of these problem behaviors for some young children (Briggs-Gowan, Carter, Bosson-Heenan, Guyer \& Horwitz, 2006), and the impairments they may cause in these young children's social, family, and future academic functioning (Campbell, 2002). Although the body of research on early childhood behavior problems has grown substantially (Egger \& Arnold, 2006), there is a paucity of research that specifically addresses low-income and minority populations. This relative lack of attention to poverty as a potentially contributing factor to young children's challenging behaviors is problematic given the large number of risk factors present in many of these families. When lower socioeconomic status (SES) is included as a contextual variable in studies, it consistently places children at increased risk for the development of behavior problems (Chapman, Dube, \& Anda, 2007; van Oort, vam der Ende, Wadesworth, Verhulst, \& Achenbach, 2011). Low-income families are at higher risk for family and social stressors (e.g., job loss, poor quality child care, inadequate supervision, unaddressed medical issues, maternal mental health issues, and unsafe neighborhoods) which in turn, negatively impact parenting practices that have been found to be related to the development and exacerbation of behavior problems in children (Linver, Brooks-Gunn, \& Kohen, 2002; Qi \& Kaiser, 2003). Knowing the prevalence of early childhood disruptive 
behavior problems in this population is an important first step towards better understanding the nature and scope of these behavior problems in this already at-risk group of children.

Challenging behaviors including noncompliance, limited emotional regulation (severe tantrums), property destruction, selfinjury and aggression are common during early childhood (Wakschlag et al., 2007). At times, these challenging behaviors can reach a level of intensity and frequency that may require professional attention. Incidence rates of behavior problems in early childhood that rise to clinical levels have been established within the general population of preschool children and range between 8-17\% (Briggs-Gowan, Carter, Skuban, \& Horwitz, 2001; Egger \& Angold, 2006; Furniss, Beyer, \& Guggenmos, 2006); Lavigne et al., 2009). In comparison, fewer studies provide incidence rates for low-income populations. Del'Homme et al., (1994) found $23 \%$ of the 42 preschool children in their small Head Start sample (29\% African American, 71\% Latino; 95\% government assistance; 63\% males) were at risk for behavior problems. Feil, Walker, Severson, and Ball (2000) surveyed 954 parents of children (3-4 years old) enrolled in Head Start and found $52 \%$ of the children met criteria for referral to mental health services for behavior and emotional problems. Other studies have reported a range of 20-33\% for behavior problems in young children from lower SES backgrounds (Gross, Sambrook, \& Fogg, 1999; Kaiser, Hancock, Cai, Foster, \& Hester, 2000). Most available studies that have included poverty as a contextual variable in the development and maintenance of behavior problems in young children have tended to examine children in special programs such as Head Start or in clinicreferred samples. The present study was designed to establish baseline rates of behavior problems in a representative urban sample of toddlers and preschoolers from low-income families.

Given the paucity of literature that addresses behavior problems in young children from impoverished backgrounds, we did not generate specific hypotheses for this study. Instead, the following general research questions were developed to guide the analyses of the data: 1) how often do challenging behaviors occur in young children from low-income families; 2) do rates of challenging behaviors in low-income populations vary based on the child's gender, ethnicity or age; and 3) how many young children have behavior problems at Francis (Routledge) does not grant permission for this article to be further copied/distributed or hosted elsewhere without the express permission from Taylor \& Francis (Routledge). 
NOT THE PUBLISHED VERSION; this is the author's final, peer-reviewed manuscript. The published version may be accessed by following the link in the citation at the bottom of the page.

the upper end of the frequency continuum that could benefit from further evaluation and possible intervention?

\section{Method}

\section{Participants}

The sample was comprised of 357 children between 1-5 years of age with both genders well represented (167 girls; 190 boys). An effort was made to obtain a stratified, representative sample based on the family's race in comparison to available population statistics from a large, Midwestern, urban area (DeNavas-Walt, Proctor, Smith, \& U.S. Census Bureau, 2008). The primary site for this project was a health clinic in an urban children's hospital that annually served over 1,500 young children from low-income families. Approximately $90 \%$ of our sample was obtained from this setting. The remaining children were obtained from three early childhood education centers ( $8 \%)$ and one day care and one birth-to-three agency (2\%). Research assistants were available at the primary hospital site during two separate time frames (8-11:30 a.m.; 1:00 -4:00 p.m.) three days each week (Monday, Wednesday, and Thursday) to increase the representativeness of the sample. During these periods, all parents and caregivers of children five years of age and younger were approached to participate in this study. Data collection at school and community sites occurred during parent orientation meetings or community events.

Because the goal of this study was to identify behavior problems in a developmentally healthy sample of low-income children, children with significant developmental, physical or health disabilities such as autism, cerebral palsy, or significant medical illnesses were excluded from the study after prescreening. Children with caregivers who could not speak English were also excluded.

Children were approximately equally distributed in terms of child gender (46.8\% girls). The mean age of children was 3.56 years old $(S D=1.26)$. The ethnic demographic characteristics of the sample closely matched those of the low-income, large Midwestern urban population (DeNavas-Walt, Proctor, Smith, \& U.S. Census Bureau, 2008) from which they were drawn (see Table 1); $74 \%$ of children 
were members of ethnic minority groups. The children's primary caregivers (i.e., respondents) were mostly female ( $n=320,89.6 \%$ ). Caregiver ages ranged from $15-65$ years $(M=28.06, S D=7.66)$. Caregiver education levels ranged from 8-18 years of school $(M=$ $12.72, S D=1.84)$; family size varied from one to eight children with a mean family size of 2.73 children $(S D=1.49)$.

The families' low-income status was defined as their total annual income falling below the poverty threshold based on the size of the family and the number of related children less than 18 years of age living in the home (U.S. Census Bureau, 2002). All families in the present study met the federal criteria for poverty; $38.1 \%$ reported an annual household income of less than $\$ 10,000 ; 26.9 \%$ earned $\$ 10,000-\$ 19,000,22.1 \%$ earned $\$ 20,000-\$ 29,000$ and the remaining $12.9 \%$ indicated an annual family income above $\$ 30,000$.

\section{Procedures}

This study was reviewed and approved by the Internal Review Boards of both the second and third authors' institutions (the first author was a doctoral student at the second author's institution at the time of data collection for this study). Parents willing to participate were asked to sign two informed consent forms for the study, one from each participating institution, and were given the opportunity to ask the research assistants questions. For parents younger than 18 years old, their legal guardians' informed consent was obtained. Consenting caregivers completed a demographic form and the Early Childhood Behavior Screen (Holtz \& Fox, 2012). Researchers read the items to parents unless the parent expressed the desire to complete the survey independently. Upon completion of the survey, each family received a five-dollar gift certificate for a local grocery store and a children's book. Parents who expressed concerns about their children's behavior or scored at least one standard deviation above the mean on the ECBS' Challenging Behavior Scale were provided information about a local mental health clinic that specialized in serving young children from families in poverty (Fox, Keller, Grede, \& Bartosz, 2007).

\section{Measures}

Demographic Questionnaire. The demographic questionnaire included the child's date of birth, ethnicity and gender, along with 
parent gender, age, ethnicity, and education level. The parents were also asked to indicate the number of children living in the home and the total household income, which were presented in $\$ 10,000$ ranges.

Early Childhood Behavior Screen (ECBS). The current study was part of a larger field-testing of the ECBS. The present study included only families who met the criteria for living in poverty. The original study (Holtz \& Fox, 2012) included families from all income levels. The ECBS is a 20 item self-report instrument developed specifically for toddlers and preschool children from low-income backgrounds. Items were developed to measure both prosocial (positive behavior scale 10 items) and challenging behaviors of early childhood (challenging behavior scale - 10 items) and were written at a 3.9 grade level. Caregivers rated each item based on their perception of their child's behavior over the past week using a three-point Likert rating scale (1 = almost never, occurs rarely or never; 2 = sometimes, occurs weekly; 3 = almost always, occurs at least daily). Total scores on the challenging behavior scale ranged from 10 to 30 with higher scores indicating a higher frequency of challenging behaviors; total scores on the positive behavior scale had the same range with higher scores indicating a higher frequency of positive behaviors.

Field-testing of the ECBS was conducted with a representative, diverse sample of 439 parents from an urban community. Examination of reliability of the ECBS in the original field-testing study found the Challenging Behavior Scale (.87) and Positive Behavior Scale (.92) obtained good levels of internal consistency. The 10-item Challenging Behavior Scale demonstrated adequate levels of concurrent validity ( $r$ $=.75$ ) with the Eyberg Child Behavior Inventory (ECBI; Eyberg \& Pincus, 1999), a 36-item measure that assesses common behavior problems in children (ages 2-16). The ECBS Challenging Behavior Scale acquired adequate levels of sensitivity ( $82 \%)$, and specificity $(80 \%)$ based on its relationship with the Eyberg Child Behavior Inventory. For the present sample, the reliability of the Challenging Behavior Scale was .86 and .94 for the Positive Behavior Scale.

\section{Results}

Table 2 presents the percentage, means, and standard deviations for each of the items on the ECBS' Challenging and Positive Behavior Scales for the present sample by ethnic group. This table 
provides data relevant for the first research question regarding what behavior problems and how often they occurred in this sample of young children based on their parents' perceptions. Based on the mean item scores for the Challenging Behavior items, temper tantrums, bothers others, hits others, takes toys away from others, and refuses to go to bed appear to be the most common challenging behaviors for their parents. Mean scores on the positive behavior items tended to be higher than the challenging behaviors.

\section{Challenging Behaviors Items}

A series of chi-square analyses were computed to identify associations between the children's gender and ethnicity (African American, Caucasian, Latino) and the frequency of their challenging behaviors (i.e., almost never, sometimes, often). For purposes of interpretation, the percentage of parents who rated their children's challenging behaviors as occurring sometimes or often was combined. The following significant gender differences were found for challenging behaviors: throws things at others $\left[\chi^{2}(2,357)=9.80, p=.007\right]$ $\left[60 \%\right.$ boys; $43 \%$ girls]; and kicks others $\left[\chi^{2}(2,357)=9.02, p=.01\right]$ $25 \%$ girls; $40 \%$ boys]. The following significant ethnic differences was found for challenging behaviors among African American (AA), Caucasian (C) and Latino (L) children: takes toys away from others $\left[\chi^{2}\right.$ $(3,357)=10.11, p=.04][C=76 \%, A A=60 \%, L=51 \%]$. In order to compare the parents' ratings on individual items of the ECBS based on their children's age, we used a median split of the children's ages to create a younger and older group. The median age for the sample was 3.71 years. $T$-tests were used to determine differences in scores on the Challenging Behavior Scale items. Significant differences were found for six of the ten items: hits others $[t(351)=2.81, p=.005]$ (younger $M=1.87, S D=0.70$; older $M=1.66, S D=0.68$ ); throws things at others $[t(351)=3.90, p<.001]$ (younger $M=1.79, S D=$ 0.71 ; older $M=1.51, S D=0.66)$; has temper tantrums $[t(351)=$ 3.32, $p=.001$ ] (younger $M=2.03, S D=0.65$; older $M=1.80, S D=$ 0.66 ); hurts others $[t(351)=2.04, p=.042]$ (younger $M=1.41, S D$ $=0.62$; older $M=1.28, S D=0.53)$; takes toys away from others $[t(351)=4.52, p<.001]$ (younger $M=1.91, S D=0.65$; older $M=$ $1.60, S D=0.65)$; and kicks others $[t(351)=2.09, p=.037]$ (younger $M=1.47, S D=0.66$; older $M=1.34, S D=0.57$ ). 
NOT THE PUBLISHED VERSION; this is the author's final, peer-reviewed manuscript. The published version may be accessed by following the link in the citation at the bottom of the page.

\section{Positive Behavior Items}

A second series of chi-square analyses were computed to identify associations between the child's gender and ethnicity and the frequency of their positive behaviors. For purposes of interpretation, the percentage of parents who rated their children's positive behaviors as occurring sometimes or often was combined. There were no significant relationships found between the child's gender and items on the ECBS positive scale. There were several relationships found between the children's' ethnicity and the caregivers' rating of positive behaviors including: eats with a spoon $\left[\chi^{2}(3,357)=20.05, p<\right.$ $.001][56 \% \mathrm{AA}, 74 \% \mathrm{~L}, 81 \% \mathrm{C}]$; listens to you $\left[\chi^{2}(3,357)=14.39, p\right.$ $=.006][36 \% \mathrm{AA}, 78 \% \mathrm{~L}, 84 \% \mathrm{C}]$; understands you $\left[\chi^{2}(3,357)=\right.$ $24.33, p<.001]\left[60 \%\right.$ AA, 76\% L, 84\% C]; does what you ask $\left[\chi^{2}(3\right.$, $357)=17.22, p=.002][70 \% \mathrm{AA}, 73 \% \mathrm{~L}, 84 \% \mathrm{C}]$; plays well with others $\left[\chi^{2}(3,357)=10.57, p=.03\right][67 \% A, 76 \% L, 81 \% \mathrm{C}]$; sleeps through the night $\left[\chi^{2}(3,357)=16.52, p=.002\right][61 \% A A, 82 \% L$, $80 \% \mathrm{C}]$; helps others $\left[\chi^{2}(3,357)=10.01, p=.04\right][69 \%$ AA, $82 \% \mathrm{~L}$, $80 \% \mathrm{C}]$; eats well $\left[\chi^{2}(3,357)=17.23, p=.002\right][65 \% \mathrm{AA}, 82 \% \mathrm{~L}$, $85 \% \mathrm{C}] ;$ and cooperates in getting dressed $\left[\chi^{2}(3,357)=27.71, p\right.$ $<.001$ ] [59\% AA, 76\% L, 82\% C]. In order to explore a possible age explanation of these ethnic differences, an analysis of variance was calculated between the three ethnic groups by the children's chronological age. A significant age effect was found $[F(2,354)=$ $4.81, p=.009]$. Scheffe's post hoc test showed that AA children were significantly $(p=.012)$ older $(M=3.72$ years, $S D=1.23)$ than $C$ children $(M=3.26$ years, $S D=1.24)$; L children's ages $(M=3.43$ years, $S D=1.30$ ) did not differ from either AA or $C$ children. Using a t-test to compare younger and older children based on the median split age of 3.71 years, there were no significant differences between the younger or older children on any of the Positive Behavior Scale items.

\section{Analyses of Total Scores for the ECBS Challenging and Positive Behavior Scales}

Total scores were computed for the ECBS Challenging Behavior and Positive Behavior scales. To compare children's ratings on the ECBS total Challenging Behavior scores based on their gender, $t$-tests were computed. Boys received significant higher scores $[t(355)=$ 
$2.60, p=.01](M=17.02, S D=4.54)$ than females $(M=15.83, S D=$ 4.03); boys and girls did not differ on the Positive Behavior scale. Separate analyses of variance (ANOVA) were computed with total scores on the Challenging and Positive Behavior scales by the children's ethnicity. A significant effect was found for the Positive Behavior scale $[F(2,354)=9.68, p<.001]$ but not for the Challenging Behavior Scale. Scheffe's post hoc test showed that African American children received significantly lower parental ratings on the Positive Behavior scale $(M=19.91, \mathrm{SD}=6.88)$ than either Caucasian $(M=22.98, \mathrm{SD}=5.28, p=.001)$ or Latino children $(M=$ $22.98, \mathrm{SD}=6.99, p=.008$ ); the latter two groups did not differ from each other. A median split was again used to divide the children into a younger and older group. The median age for the sample was 3.71 years. To compare younger and older children on the ECBS scales, $t$ tests were used. The results showed that younger children had significant higher scores on the Challenging Behavior scale $[t(355)=$ $3.07, p=.002](M=17.16, S D=4.27)$ than the older children $(M=$ $15.76, S D=4.32$ ); the younger and older children did not differ on the Positive Behavior scale.

It is often customary in clinical settings to identify children in potential need of further, more comprehensive evaluations for possible mental health services if they score at least a standard deviation above the mean (approximately the $85^{\text {th }}$ percentile) on a measure of externalizing behavior problems (Achenbach, 1991). Using this approach for the ECBS Challenging Behavior scale, the cutoff raw score for one standard deviation above the samples mean score was 20.81 . Based on our sample, $17.4 \%$ met or exceeded this cutoff score. Based on a series of chi square analyses using this cutoff score (met or did not meet it) and the children's gender, ethnicity, and age (younger, older) no significant relationships between these demographic variables and meeting or exceeding the cutoff score were found (all ps > .05).

\section{Discussion}

This study investigated the frequency of behavior problems in an ethnically diverse, representative, Midwestern sample of children between one and five-years of age who were living below the federally-defined threshold for poverty. When combining parent ratings of sometimes and often, the frequency of externalizing behaviors such The Journal of Psychology: Interdisciplinary and Applied, Vol. 149, No. 2 (2015): pg. 161-174. DOI. This article is (C) Taylor \& Francis (Routledge) and permission has been granted for this version to appear in e-Publications@Marquette. Taylor \& Francis (Routledge) does not grant permission for this article to be further copied/distributed or hosted elsewhere without the express permission from Taylor \& Francis (Routledge). 
as tantrums, bothering or hitting others was common in this sample ( $60 \%$ or higher). The higher rate of challenging behavior in lowincome populations is most likely due to a combination of family and environmental factors. Developmental studies of behavior problems suggest the child's temperament in combination with environment factors leads to the development and exacerbation of behavioral difficulties (Rutter, 2000, 2003, 2005). There is no evidence that children from low-income families have a genetic predisposition to develop a more challenging temperament than that of children from middle or higher income families. There are, however, a number of environmental factors related to living in poverty that may have adverse implications for low-income children. For example, low-income families are at higher risk for job loss, poor child care, inadequate supervision, and maternal mental health issues which in turn, may negatively impact the caretakers' ability to provide nurturing and stable environment for their children (Gross et al., 2009; Linver et al., 2002; Qi \& Kaiser, 2003). These and other risk factors related to poverty (e.g., premature birth, malnutrition, harsher parenting practices, single headed households, marital conflict, and poorer quality schools) compound a child's risk for the development of behavior problems and makes the child more susceptible negative outcomes (Chapman et al., 2007; Rutter, 2000).

Gender differences were found in the present study with boys demonstrating higher rates of externalizing behaviors. This finding is consistent with prior research suggesting that gender differences in behavior problems are notable in early childhood with boys being more likely to engage in externalizing behaviors (Baillargeon et al., 2007; Mesman, Bongers, \& Koot, 2001). Previous studies also have indicated challenging behaviors occur at different rates based on a child's age and developmental level (Campbell, 2002) with externalizing behaviors gradually diminishing over time (Fanti \& Henrich, 2010). In the current study, and consistent with the literature, younger children received higher scores on six of the ten items on the Challenging Scale than older children. Last, ethnicity does not appear to play a significant role in early child behavior problems with only one challenging behavior identified as significant (takes toys away from others). Given that we did not collect information on how many children were involved in programs outside of their home (e.g., Head Start, day cares), this 
finding may reflect an artifact of each group's level of external involvement and would require additional research to ferret out.

This study also focused on the children's positive behaviors, an area often ignored in studies of young children's behavior problems. The results suggested that normal developmental behaviors expected as children mature were present in this sample at relatively high rates (e.g., eats with a spoon, understands you, helps others) and were not related to the child's gender or age. Ethnicity did appear to be a significant factor in children's positive behaviors. However, African American children were significantly older than Caucasian but not Latino children. Some of the items on the Positive Scale appear to be developmental in nature. Consequently, as children mature, a parent is more likely to rate items such as eats with a spoon or cooperates in getting dressed as never occurring because the children use other eating utensils and get dressed on their own. For the items that reflected more positive behaviors that would be less developmentally related, fewer African American children appeared to cooperate as well with their caregivers (listens to you, understands you, does what you ask, sleeps through the night) as Caucasian or Latino counterparts. While the older age of the African American children and the higher percentage of African Americans in the sample could be possible factors, perhaps the parenting practices of African American participants differ in that less attention is provided young children for exhibiting positive behaviors. Clearly, the role of ethnicity in the development of positive behaviors in young children deserves further study.

Last, using an $85^{\text {th }}$ percentile cutoff score to identify children, whose challenging behaviors were more frequent, $17.4 \%$ of the sample, met this criterion. This rate of behaviors is at the higher end of rates reported in the literature for younger children with "clinical levels" of externalizing behaviors (Briggs-Gowan et al., 2001; Egger \& Angold, 2006; Furniss et al., 2006; Lavigne et al., 2009) and was not related to the present sample's age, gender or ethnicity. When compared to samples of low-income children reported in the literature, our $17.4 \%$ rate is relatively low (e.g., Del'Homme et al., (1994) $23 \%$; Feil et al., 2000 - 52\%), but is closer to the reported range of 20-33\% for behavior problems in young children from lower SES backgrounds (Gross et al, 1999; Kaiser et al., 2000). It is likely that 
the sampling methods, definitions of clinical behavior problems, and measurement tools contributed to the variance in finding across studies. However what is clear is the finding that poverty is an important contextual factor in the development of higher levels of significant behavior issues in young children.

\section{Limitations}

There were a number of limitations in the present study. While the sample did closely represent the population it was selected from, it was a convenience sample from a minimum number of sites and therefore could be influenced by selection bias. The study did not include caregivers who were non-English Speakers. The study was based on parental self-report and relied on a relatively brief screening tool for identifying challenging behaviors in young children. Parent surveys, however, are often the primary means to obtain information regarding child behavior. Behavior rating measures require parents to make judgments about their child's level of behavioral functioning, but they can also be accurate predictors of behavior problems in children (Bergman, 2004). However, more extensive evaluations would be warranted, particularly for children scoring at the higher end of the challenging behavior range, to determine if a clinical diagnosis was warranted and treatment was needed. We also computed several separate analyses of individual child behaviors which increases the chance of finding significance (Type I error). Last, we collapsed parents' ratings of "sometimes" and "often" in our analyses.

\section{Implications}

This study along with the existing literature suggests behavior problems are frequent in early childhood and may occur at higher rates in low-income populations. Unfortunately, existing research on treatment provision has found only a small percentage of children who need mental health services actually obtain them (e.g., Lavigne et al., 2009). This ongoing issue has at least three contributing factors: 1 ) the lack of universal screening for behavior problems in young children; 2) the small number of mental health training programs that address young children resulting in relatively few professionals who can competently address behavioral concerns in these families; and 3) the limited number of evidence-based programs for addressing behavior problems in children living in poverty that have been

The Journal of Psychology: Interdisciplinary and Applied, Vol. 149, No. 2 (2015): pg. 161-174. DOI. This article is @ Taylor \& Francis (Routledge) and permission has been granted for this version to appear in e-Publications@Marquette. Taylor \& Francis (Routledge) does not grant permission for this article to be further copied/distributed or hosted elsewhere without the express permission from Taylor \& Francis (Routledge). 
successfully extended to community-based settings (Fox \& Holtz, 2009; Fox, Mattek, \& Gresl, 2013). Clearly more attention needs to be paid to our most vulnerable young children to prevent them from continuing to experience significant behavior problems that are likely to persist and even escalate well beyond early childhood.

\section{References}

1. Achenbach, T. M. (1991). Manual for the Child Behavior Checklist 4-18 and 1991 Profile. Burlington, VT: Department of Psychiatry, University of Vermont.

2. Baillargeon, R.H., Normand, C.L., Seguin, J.R., Zoccolillo, M., Japel, C., Perusse, D., et al. (2007). The evolution of problem and social competence behaviors during toddlerhood: A prospective populationbased cohort survey. Infant Mental Health Journal, 28 (1), 12-38.

3. Bergman, D. (2004). Screening for behavioral developmental problems: Issues, obstacles, and opportunities for change. Portland, ME: National Academy for State Health Policy.

4. Biglan, A., Mrazek, P.J., Carnine, D., \& Flay, B.R. (2003). The integration of research and practice in the prevention of youth problem behaviors. American Psychologist, 58, 433-440.

5. Briggs-Gowan, M.J., Carter, A. S., Bosson-Heenan, J., Guyer, A. E., \& Horwitz, S. M. (2006). Are infant-toddler social-emotional and behavioral problems transient? Journal of the American Academy of Child and Adolescent Psychiatry, 45, 849-858.

6. Briggs-Gowan, M.J., Carter, A.S., Skuban, E.M., \& Horwitz, S.M. (2001). Prevalence of social-emotional and behavioral problems in a community sample of 1 - and 2- year-old children. Journal of the American Academy of Child and Adolescent Psychiatry, 40, 811-819.

7. Campbell, S. (2002). Behavior problems in preschool children: Clinical and developmental issues ( $2^{\text {nd }}$ Ed.). New York: Guilford Press.

8. Chapman, D.P., Dube, S.R., \& Anda, R.F. (2007). Adverse childhood events as risk factors for negative mental health outcomes. Psychiatric Annals, 37(5), 359-364.

9. Del'Homme, M.A., Sinclair, E., Kasari, C., \& Sigman, M. (1994). Preschool children with behavioral problems: Observation in instructional and free play contexts. Behavioral Disorders, 19, 221-232.

The Journal of Psychology: Interdisciplinary and Applied, Vol. 149, No. 2 (2015): pg. 161-174. DOI. This article is @ Taylor \& Francis (Routledge) and permission has been granted for this version to appear in e-Publications@Marquette. Taylor \& Francis (Routledge) does not grant permission for this article to be further copied/distributed or hosted elsewhere without the express permission from Taylor \& Francis (Routledge). 
NOT THE PUBLISHED VERSION; this is the author's final, peer-reviewed manuscript. The published version may be

accessed by following the link in the citation at the bottom of the page.

10. Denavas-Walt, C., Proctor, B.D., Smith, J.C., \& U.S. Census Bureau. (2008). Income poverty and health insurance coverage in the United States in 2007. Current populations reports, 60-235. Washington, D.C.: U.S. Government Printing Office.

11. Egger, H.E., \& Angold, A. (2006). Common emotional and behavioral disorders in preschool children: Presentation, nosology, and epidemiology. Journal of Clinical Child Psychology and Psychiatry, 47, 313-337.

12. Eyberg, S.M., \& Pincus, D. (1999). Eyberg Child Behavior Inventory and Sutter-Eyberg Student Behavior Inventory-Revised professional manual. Odessa, FL: Psychological Assessment Services.

13. Fanti, K. A., \& Henrich, C. C. (2010). Trajectories of pure and cooccurring internalizing and externalizing problems from age 2 to age 12 : Findings from the National Institute of Child Health and Human Development study of early child care. Developmental Psychology, 46, 1159-1175,

14. Feil, E.G., Walker, H., Severson, H., \& Ball, A. (2000). Proactive screening for emotional/behavioral concerns in head start preschools: Promising practices and challenges in applied research. Behavioral Disorders, 26, 13-25.

15. Fox, R.A., \& Holtz, C.A. (2009). Treatment outcomes for toddlers with behavior problems and developmental delays from low-income families. Child and Adolescent Mental Health, 14 (4), 183-189.

16. Fox, R. A., Keller, K. M., Grede, P. L., \& Bartosz, A. M. (2007). A mental health clinic for toddlers with developmental delays and behavior problems. Research in Developmental Disabilities, 28, 119-129.

17. Fox, R.A., Mattek, R. J., \& Gresl, B. L. (2013). Evaluation of a universitycommunity partnership to provide home-based, mental health services for children from families living in poverty. Community Mental Health Journal, 49, 599-610.

18. Furniss, T., Beyer, T., \& Guggenmos, J. (2006). Prevalence of behavioural and emotional problems among six-years-old preschool children: Baseline results of a prospective longitudinal study. Social Psychiatry and Psychiatric Epidemiology, 41, 394-399.

19. Gross, D., Sambrook, A., \& Fogg, L. (1999). Behavior problems among young children in low-income urban daycare centers. Research in Nursing and Health, 22(1), 15-25.

The Journal of Psychology: Interdisciplinary and Applied, Vol. 149, No. 2 (2015): pg. 161-174. DOI. This article is (C) Taylor \& Francis (Routledge) and permission has been granted for this version to appear in e-Publications@Marquette. Taylor \& Francis (Routledge) does not grant permission for this article to be further copied/distributed or hosted elsewhere without the express permission from Taylor \& Francis (Routledge). 
20. Gross, H.E., Shaw, D.S., Burwell, R.A., \& Nagin, D.S. (2009). Transactional processes in child disruptive behavior and maternal depression: A longitudinal study from early childhood to adolescence. Development and Psychopathology, 21, 139-156.

21. Holtz, C.A., \& Fox, R.A. (2012). Behavior problems in young children from low-income families: The development of a new screening tool, Infant Mental Health Journal, 33(1), 82-94.

22. Kaiser, A.P., Hancock, T.B., Cai, X., Foster, E.M., \& Hester, P.P. (2000). Parent-reported behavior problems and language delays in boys and girls enrolled in Head Start classrooms. Behavioral Disorders, 26(1), 26-41.

23. Lavigne, J.V., LeBailly, S.A., Hopkins, J., Gouze, K.R., \& Binns, H.J. (2009) The prevalence of ADHD, ODD, Depression, and Anxiety in a community sample of 4-year-olds. Journal of Clinical Child and Adolescent Psychology, 38(3), 315-328.

24. Linver, M.R., Brooks-Gunn, J., \& Kohen, D.E. (2002). Family processes as pathways from income to young children's development. Developmental Psychology, 38, 719-734.

25. Mesman, J., Bongers, I.L., \& Koot, H. (2001). Preschool developmental pathways to preadolescent internalizating and externalizing problems. Journal of Child Psychology and Psychiatry, 42, 679-689.

26. van Oort, F. V. A., van der Ende, J., Wadsworth, M. E., Verhulst, F. C., \& Achenbach, T. M. (2011). Cross-national comparison of the link between socioeconomic status and emotional and behavioral problems in youths. Social Psychiatry and Psychiatric Epidemiology, 46, 167172.

27. Qi, C. H., \& Kaiser, A. P. (2003). Behavior problems of preschool children from low-income families: Review of the literature. Topics in Early Childhood Special Education, 23, 188-216.

28. Rutter, M. (2000). Psychosocial influences: Critiques, findings, and research needs. Development and Psychopathology, 12, 375-405.

29. Rutter, M. (2003). Poverty and child mental health: Natural experiments and causation. Journal of the American Medical Association, 290, 2063-2064.

30. Rutter, M. (2005). Environmentally mediated risks for psychopathology: Research strategies and findings. Journal of the American Academy of Child and Adolescent Psychiatry, 44, 3-18.

The Journal of Psychology: Interdisciplinary and Applied, Vol. 149, No. 2 (2015): pg. 161-174. DOI. This article is (C) Taylor \& Francis (Routledge) and permission has been granted for this version to appear in e-Publications@Marquette. Taylor \& Francis (Routledge) does not grant permission for this article to be further copied/distributed or hosted elsewhere without the express permission from Taylor \& Francis (Routledge). 
NOT THE PUBLISHED VERSION; this is the author's final, peer-reviewed manuscript. The published version may be accessed by following the link in the citation at the bottom of the page.

31. U.S. Census Bureau (2002). Poverty in the United States: 2001. Washington DC: U.S. Government Printing Office.

32. Wakschlag, L.S., Briggs-Gowan, M.J., Carter, A.S., Hill, B.D., Keenan, K., McCarthy, K.J., et al. (2007). A developmental framework for distinguishing disruptive behaviors from normative misbehavior in preschool children. Journal of Child Psychology and Psychiatry, 48, 976-987.

Table 1. Ethnic Demographics of Study Sample and Low-Income Midwestern Urban Population of Families with Young Children (U.S. Census Data, 2000)

\begin{tabular}{lccl} 
& Sample: Child & Sample: Parent & $\begin{array}{l}\text { Population: Urban } \\
\text { Child and Adult }\end{array}$ \\
\cline { 2 - 4 } & $207(58.0 \%)$ & $209(58.5 \%)$ & $53,504(57 \%)$ \\
Black & $93(26.1 \%)$ & $96(26.9 \%)$ & $23,872(25 \%)$ \\
White & $55(15.4 \%)$ & $50(14.0 \%)$ & $15,039(16 \%)$ \\
Hispanic & $2(0.5 \%)$ & $2(0.5 \%)$ & $1,787(1.8 \%)$ \\
Other & 357 & 357 & 94,202 \\
Total & & &
\end{tabular}

The Journal of Psychology: Interdisciplinary and Applied, Vol. 149, No. 2 (2015): pg. 161-174. DOI. This article is @ Taylor \& Francis (Routledge) and permission has been granted for this version to appear in e-Publications@Marquette. Taylor \& Francis (Routledge) does not grant permission for this article to be further copied/distributed or hosted elsewhere without the express permission from Taylor \& Francis (Routledge). 
NOT THE PUBLISHED VERSION; this is the author's final, peer-reviewed manuscript. The published version may be accessed by following the link in the citation at the bottom of the page.

Table 2. Percentages, Means, and Standard Deviations of African American (AA), Caucasian (C), and Latino (L) Parent-Reported Challenging and Positivel Behaviors in Children

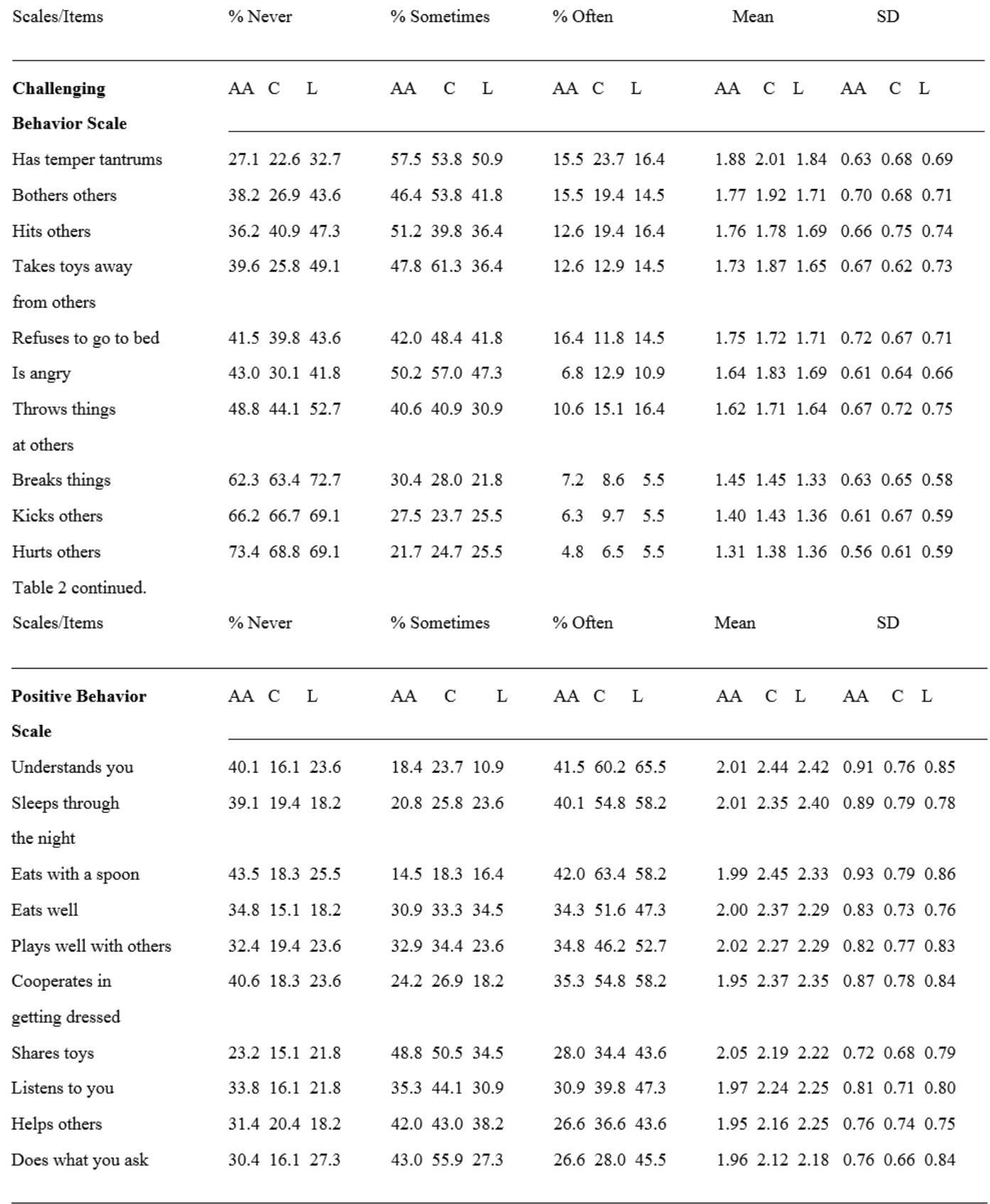

The Journal of Psychology: Interdisciplinary and Applied, Vol. 149, No. 2 (2015): pg. 161-174. DOI. This article is (C) Taylor \& Francis (Routledge) and permission has been granted for this version to appear in e-Publications@Marquette. Taylor \& Francis (Routledge) does not grant permission for this article to be further copied/distributed or hosted elsewhere without the express permission from Taylor \& Francis (Routledge). 